\title{
Role of multidetector computed tomography in diagnosis acute aortic syndrome
}

\author{
Dragan Javoran* \\ Thalassotherapia Opatija - Clinic for treatment, rehabilitation and prevention of cardiovascular \\ disease, Opatija, Croatia
}

Acute aortic syndrome (AAS) is the modern term that includes aortic dissection, intramural hematoma $(\mathrm{IMH})$, and penetrating atherosclerotic ulcer (PAU and aortic rupture); trauma to the aorta with intimal laceration may also be considered.

The common denominator of AAS is a disruption of the media layer of the aorta with bleeding within $\mathrm{IMH}$, along the aortic media resulting in the separation of the layers of the aorta (dissection), or transmurally through the wall in the case of a ruptured PAU or trauma.

Multidetector computed tomography (MDCT) is a gold standard due to its intrinsic diagnostic value; its performance approaches $100 \%$ sensitivity and specificity, and it is accepted

Received: $17^{\text {th }}$ Apr 2014

*Address for correspondence: Thalassotherapia Opatija, Maršala Tita 188/1, HR51410 Opatija, Croatia.

Phone: +385-91-2605444

E-mail: javoran@gmail.com as the first-line modality for the suspected acute aortic disease. MDCT allows an early recognition and characterisation od AAS as well as the presence of any associated complications.

Long-standing arterial hypertension, variety of genetic disorders with altered connective tissues, vascular inflammation, deceleration trauma and iatrogenic factors are the most prevalent risk conditions. Patients with AAS often present in a similar fashion, regardless of the underlying condition of dissection, IMH, PAU or contained aortic rupture. Pain is the most commonly presenting symptom of acute aortic dissection and should prompt immediate attention, including diagnostic imaging modalities (such as multislice computed tomography, transoesophageal ultrasound, or magnetic resonance imaging).

KEYWORDS: multidetector computed tomography management, acute thoracic aortic syndromes, aortic dissection, intramural hematoma, penetrating aortic ulcer.

CITATION: Cardiol Croat. 2014;9(5-6):195.

\section{Literature}

1. Vilacosta I, Roman JA. Acute aortic syndrome. Heart 2001;85(4):365-8.

2. Ganaha F, Miller DC, Sugimoto K, et al. Prognosis of aortic intramural hematoma with and without penetrating atherosclerotic ulcer: a clinical and radiological analysis. Circulation. 2002;106(3):342-8.

3. Reddy GP. Multidetector CT of acute aortic syndrome. Imag Decision. 2006;2:22-6.

4. Manghat NE, Morgan-Hughes GJ, Roobottom CA. Multi-detector row computed tomography: imaging in acute aortic syndrome. Clin Radiol. 2005;60:1256-67.

5. Stillman AE, Oudkerk M, Ackerman M, et al. Use of multidetector computed tomography for the assessment of acute chest pain: a consensus statement of the North American Society of Cardiac Imaging and the European Society of Cardiac Radiology. Int J Cardiovasc Imaging. 2007;23:415-27. 